and the only published examples are the sample papers distributed by the Royal College. Dr Puri and Dr Sklar's interpretation is not that of the College. It may be useful to emphasise that the only guidance issued by the Examinations Office is that in the Regulations and the Sample Question Papers.

Dr Sheila A. ManN Chief Examiner

\section{Predicting new patient non-attendance}

\section{DeAR SirS}

We were interested to read Dr Woods' study (Psychiatric Bulletin, January 1992 16, 18-14) suggesting that psychiatrists are poor at predicting non-attendance on the basis of the patient's referral letter. We have data suggesting that, within a particular clinic, more accurate prediction may be possible.

Recently, the rate of non-attendance at the new patient general psychiatry clinic conducted by the authors has been found to be in excess of $30 \%$. We compared the referral letters of 18 non-attenders with those of 18 patients who had attended during the same three month period.

The two groups did not differ in age, sex, time of appointment offered, length of time between referral and appointment or in whether an urgent or routine appointment had been requested.

Marked differences were evident in the content of the referral letters, cross-tabulations using the SPSS system revealing significant associations between the patient not attending and the following four factors: (a) the letter being addressed to 'first available clinic' rather than to a named consultant $(P<0.05)$

(b) the referral letter being handwritten $(P<0.001)$

(c) the letter containing no reference to a diagnosis, no matter how approximate or vague $(P<0.01)$

(d) the letter containing no reference to the possible reasons for the patient's problems, nor to their social situation or background $(P<0.01)$.

In addition, a highly significant association was found between non-attendance and the patient not responding to a request, sent with details of their appointment, to confirm, by phone or letter, that they would be attending their appointment $(P<0.001)$.

Stepwise logistic regression analysis suggested that the two most influential of these factors were the patients not confirming their intention to attend and the referral letter containing no reference to the reasons for, or context of, their difficulties. Taken together, these two factors correctly predicted whether the individual would have attended in 35 out of the 36 cases.

The strong correlations between non-attendance and elements in the referral letter may not have a simple explanation; however we suggest that there may be a relationshp with the psychiatric skills of the referring general practitioner, the handwritten referral letter, devoid of information other than the patient's symptoms, reflecting a hurriedly-made referral, possibly after a difficult interchange with the patient, who is himself uncommitted to the referral and who consequently ignores the letter he receives from the hospital.

A new patient non-attendance rate of $30 \%$ is undoubtedly costly in time and resources. These findings suggest that an effective way of reducing this wastage may be to identify patients at high risk of non-attendance by screening new patient referral letters for the four elements identified above and requesting information from patients of their intention to attend. Extra efforts could then be made, which may involve the GP, to contact these patients prior to their appointment. More radical approaches, possibly appropriate in view of the recent changes in the NHS, may be to include in contracts a charge for non-attendance or to make the new patient appointment, in non-urgent cases, conditional on confirmation from the patient.

Jonathon S. E. Hellewell

Withington Hospital

Manchester $208 L R$

North Manchester General Hospital

Elizabeth Wyn PUgh

Manchester M8 6RL

\section{In conversation with Ivor Browne}

\section{DeAR SirS}

The interview by David Healy with Professor Ivor Browne (Psychiatric Bulletin, January 1992, 16, 1-9) was most interesting and rewarding. As an Ulsterman, I was honoured to be Chairman of the Irish Division for a period during the past decade. At times I felt "all at sea" when chairing meetings in the Republic, coming from, and working in, the NHS system in the North. Now I understand more of the undercurrents medico-politically and thank those colleagues "in the know" for guiding me through hazardous waters. I could sense antagonism between protagonists, yet all were courteous, and none more so than Ivor who occasionally appeared to steer a course at odds with other viewpoints.

In an "off the cuff" conversation memory can lapse. That must surely have happened to Ivor about the University chair in Belfast. The late John Gibson became Professor of Mental Health at Queens University, Belfast in 1957, and developed psychiatry in N. Ireland for 17 years before his untimely death in 1974, to be followed by George Fenton, and now Roy McClelland.

Ivor is right when he alludes to worries which psychiatrists in N. Ireland had in the ' 70 s which were why 